\title{
Connections Identified by Teacher Educators Between the Mathematics They Teach and the Mathematics Their Students Will Teach in the Future
}

\author{
Guillermo de los Ángeles ${ }^{1 *}$ (D) , Cristina Ochoviet $^{1}$ (D) , Verónica Molfino ${ }^{1}$ (D) \\ ${ }^{1}$ Department of Mathematics, Consejo de Formación en Educación, URUGUAY \\ *Corresponding Author: gui_delos@hotmail.com
}

Citation: de los Ángeles, G., Ochoviet, C., \& Molfino, V. (2022). Connections Identified by Teacher Educators Between the Mathematics They Teach and the Mathematics Their Students Will Teach in the Future. International Electronic Journal of Mathematics Education, 17(1), em0668. https://doi.org/10.29333/iejme/11472

\section{ARTICLE INFO}

Received: 27 Jul. 2021

Accepted: 22 Nov. 2021

\begin{abstract}
The relationship between the mathematics taught in teacher training and the mathematics demanded in teaching practices is an issue that has been problematized for many years in the field of Mathematics Education. Nonetheless, recent studies show it is still a focus of interest in the field. In this study, we have identified different connections that teacher educators are able to establish between the mathematics they teach and that which their students, prospective mathematics teachers, will have to teach eventually. We have conducted an in-depth case study and have identified that teacher educators establish content connections, modeled instruction connections, and disciplinary practice connections. Furthermore, we have reported the main difficulties that arise in establishing these connections. Additionally, we have identified a new type of connection, which we call professional practice connections.
\end{abstract}

Keywords: connections, teacher training, teacher educators

\section{INTRODUCTION}

In this article, we have focused on a singular aspect of mathematics teacher training: the difficulty prospective teachers face in establishing connections between the mathematics learned in teacher education programs and that which is required to be taught in secondary school. The lack of connections determines a limited construction of prospective teachers' mathematical discourses, that affect the communication of mathematical ideas in the classroom:

This issue has been dealt with in the field for over a hundred years:

The young university student found himself, at the outset, confronted with problems, which did not suggest, in any particular, the things with which he had been concerned at school. Naturally he forgot these things quickly and thoroughly. When, after finishing his course of study, he became a teacher, he suddenly found himself expected to teach the traditional elementary mathematics in the old pedantic way; and, since he was scarcely able, unaided, to discern any connection between this task and his university mathematics, he soon fell in with the time honoured way of teaching, and his university studies remained only a more or less pleasant memory which had no influence upon his teaching. (Felix Klein, 1908, referred to in Winsløw \& Grønbæk, 2014, p. 61)

Nevertheless, it is still a focus of interest in the field, as it is reported in various studies (Leikin et al., 2018; Suominen, 2018; Ticknor, 2012; Wasserman, 2018; Weber et al., 2020; Yan et al., 2021).

Leikin et al. (2018) conducted a study with mathematics teachers from teacher training courses at Israeli universities. In this study, they make a reference to the CBMS report (2001), in which it is recommended to redesign mathematics courses for future teachers in order to help them make connections between the contents they study at college-level and the mathematical contents they will have to teach in secondary education. They conclude that there is a need for a stronger impact of school-level contents on university mathematics, and that its development must begin in mathematics courses.

Suominen (2018) produced a study in which she explores the connections established by mathematicians and mathematics teachers at college-level between abstract algebra and school algebra. She identifies a wide range of mathematical connections, from three different perspectives: as a characteristic of mathematics, as an artifact for learning, and as a mathematical process or activity. Regarding the first perspective, she distinguishes five categories: alternative representations of mathematical objects, comparison through common characteristics, generalization, hierarchical relationships, and applications to the real world. This 
study accounts for the connections established by specialized mathematicians and college-level teachers, at least on a theoretical level.

Ticknor (2012) identified a problem existing between the content that prospective teachers face within their careers and the connections that exist between that content and that which they will in turn have to teach in their classes. She asserts that it is wrong to consider that the traditional curriculum for mathematics major is suitable for future secondary school mathematics teachers. It is not enough for mathematics teachers to understand advanced mathematics; they must also be able to connect the advanced contents they study during teacher training with those which they will have to teach eventually. More specifically, she analyzed a prospective mathematics teacher course in abstract algebra in the United States. Ticknor (2012) points out teacher educators should make explicit connections between the advanced mathematics they teach and the mathematics their students, prospective teachers, will teach in secondary school.

Wasserman (2018) establishes contact points between advanced mathematics and mathematics education at a secondary education level. He considers a non-exhaustive list of four different connection points in a spectrum that goes from the most linked to mathematics, to the most linked to mathematics education: content connections, disciplinary practice connections, classroom teaching connections, and modeled instruction connections.

Weber et al. (2020) experiment with an innovative model that seeks to teach advanced mathematics to be meaningful in prospective teachers' future classroom practice. They apply the model to a real analysis course focusing on concepts that prospective teachers will need to teach in secondary schools like, for example, continuity, the existence of the inverse function, and the resolution of trigonometric equations. The results show that an understanding of advanced mathematics not always helps prospective teachers cope with pedagogical situations, because teaching is not just applying the concepts of advanced mathematics to secondary mathematics, instead, a deep understanding of the secondary mathematics is needed.

Yan et al. (2021) interview 24 mathematicians from ten universities to analyze the value of advanced mathematics for secondary mathematics teachers. The interviewees affirm that advanced mathematics studies render benefits like: "(1) drawing connections across mathematical domains, (2) gaining mathematical experience for developing problem-solving abilities, and (3) increasing epistemological awareness of the subject" (p. 18). However, when participants were asked to supply specific examples of these benefits, they could not offer them in abundance.

In regards to the modeled instruction connections (Wasserman, 2018), which refer to the establishment of connections through the teaching practice itself, there are extensive studies and references made by many authors (Marshman, 2021; Rojas \& Deulofeu, 2015; Rojas et al., 2021; Ticknor, 2012) pointing out the influence that teacher educators' classroom practices have in prospective teachers' future teaching practices. Many times this influence hinders the application of what is learned in methodology courses during teacher training.

The aim of this study consists in identifying connections that teacher educators are able to establish between the mathematics they teach and the mathematics their students, prospective teachers, will need for their teaching practices. Based on the literature review carried out, we consider this work will shed light on an original question: which mathematical connections do teacher educators establish in an initial mathematics teacher training program? We have focused on mathematical connections, though taking into consideration that other types of connections could appear.

\section{CONNECTIONS}

Wasserman (2018) considers the connections between the study of advanced mathematics and secondary teaching through a non-exhaustive list of four different connection points, in a spectrum that ranges from the one most linked to mathematics to the more linked to pedagogy: Content connections, disciplinary practice connections, classroom teaching connections, and modeled instruction connections.

Wasserman (2018) refers to content connections as the relationship between the content of advanced mathematics and the content of school mathematics. Disciplinary practice connections refer to processes involved when studying advanced mathematics and those involved in studying secondary mathematics, such as "reasoning, creating, generalizing, defining, extending, and unifying" (Wasserman, 2018, p. 12-13). When discussing classroom teaching connections, he refers to the contents of advanced mathematics and how they can motivate and affect the actions of prospective teachers in the classroom, be it related to task design, designing problems with particular characteristics, interaction with students, and responses given to their questions, or sequencing activities. Concerning modeled instruction connections, the author points out that teacher educators can establish connections with secondary education through their own educational practices. That is, to develop in their own advanced mathematics classes the teaching practices recommended for secondary school.

\section{METHOD}

We have yielded a qualitative exploratory study that consists of a case study. Eight mathematics teacher educators were interviewed in an attempt to cover a diversity of mathematics courses in mathematics teacher training in Uruguay (Mathematics Fundamentals, Geometry, Calculus I, Calculus II, Probability and Statistics, Topology, Geometry, and Linear Algebra).

The teacher educators worked in six different teacher training institutions, distributed in different regions of the country. They were all practicing teachers at the time the interviews were conducted. In the selection of trainers, we sought to take into account all possible advanced mathematics courses, with teachers from different regions and with different levels of expertise, 
interviewing all teachers who agreed to participate. The interviews with the teacher educators were carried out individually and were audio-recorded.

\section{Instrument}

A semi-structured interview was designed and applied to eight teacher educators in order to identify the connections they could manage to establish between the mathematics of the courses they teach and the secondary-level mathematics, and how they visualize their role in making these connections explicit as well. The instrument was designed with the purpose of identifying mathematical connections, that is, content connections (Wasserman, 2018); however, the fact that other types of connections could emerge in the interviews was taken into consideration. Special attention was paid to this and whenever it did happen, as will be seen later, it was reported. That is, mentions of other connections were not excluded even though they were not considered amongst the aims of this work.

Below, the intentionality of each question of the instrument is explained.

1. In your opinion, why is it needed for mathematics prospective teachers to study [name of the course taught by the teacher interviewed] during teacher training?

This question is intended to analyze the position of the teacher educator regarding the importance of the course they teach in the teacher training program, and if they mention any difference with other professional careers where students study the same subject.

2. Research reports that prospective teachers are unable to make a connection between the mathematics they learn in advanced mathematics courses and the mathematics demanded for teaching secondary school mathematics. How would you explain this phenomenon?

When asking this question, an attempt will be made to observe firstly whether the teacher is aware of the problem and, secondly, how familiar they are with it.

3. State three connections between the mathematical content that you teach in [name of the course the teacher educator teaches] and the contents of secondary school mathematics.

This question seeks to observe if the teacher educator is able to identify connections between the course they teach and lower secondary school mathematics, and if they have devoted time to reflect on this in their own practice. The question addresses exclusively lower secondary education (12-14 years) since in upper secondary education (15-17 years) many contents have an almost symmetrical relationship with advanced mathematics, and it would probably be the immediate response from the interviewee. We intend to go further than this due to the fact that the importance of teacher training courses is not restricted to upper secondary education. This question is specifically looking for content connections.

4. In your opinion, is it relevant to make these connections, or others, explicit in your [name of the course the teacher educator teaches] class? Why?

With this question, it can be identified whether or not the teacher educator believes that it is important to take action in the classroom so that future teachers can establish the connections that exist between their course and the contents of secondary school mathematics.

(In case of an affirmative answer)

5. How often do you make these connections in your [name of the course the teacher educator teaches] class?

With this question, an attempt is made to recognize the actions taken by the teacher educator. That is, if in addition to considering it important to explicitly establish the connections, they actually do so in their classroom practice, and how frequently.

6. Could you mention three more connections between the contents of the course you teach and the contents of lower secondary education?

This question not only seeks to find more connections between the mathematics courses of teacher training and lower secondary education, but it also acts as a kind of control for question 5 . In other words, a teacher educator who usually makes connections in the classroom has already carried out an analysis of the contents of their course and those that their students will teach eventually. Consequently, they should be able to easily identify three more contact points.

\section{RESULTS ANALYSIS}

In this section, an analysis of the answers of the interviewed teacher educators is presented. To protect their identity, they have been named F1, F2, F3, F4, F5, F6, F7, and F8, although gender identification is kept in order to respect the different voices and offer an inclusive vision.

\section{Teacher Educator F1}

Teacher educator F1, a Calculus 2 teacher with nine years of experience in teaching the course, justified the contents of the course by stating that future teachers needs to "have knowledge that covers more than what they are going to teach" (F1), specifying that the contents of the course that she teaches are not contents that will be addressed in secondary education, and that they would be useful to students in case they consider carrying out post-graduate studies. In short, the teacher educator conceives that her course would only be important in case the future teacher wishes to carry out post-graduate studies. From her 
point of view, the course she teaches does not contribute to the professional performance of those who are in training and will work teaching mathematics at the secondary level.

F1 revealed that she is not aware of the problem of disconnection between the contents of advanced mathematics and those of secondary education that students endure. When asked for examples of connections between the course she is teaching and the contents of lower secondary education, she showed trouble. Upon insistence, she could hardly manage to list three: the irrationality of the number $e$ and the introduction of irrational numbers in lower secondary education, integrals and area calculations, and sequences of numbers, the Fibonacci sequence, and sequences of figures. However, when asked if it is important to establish connections between the contents she teaches and those of secondary education, she responded: "Yes, absolutely." (F1). In addition, she claimed to do so regularly in her class, estimating a weekly iteration. However, her statement was followed with "whenever I can" (F1), and that "sometimes I neglect that a little bit" (F1). Furthermore, when asked to give three new examples of connections between the subject she teaches and the contents of secondary education, she was unable to fulfill the task. It is contradictory that, in an annual course, when establishing connections on a weekly basis, the teacher educator could not remember six of these connections. In summary, several contradictions can be appreciated in the teacher's speech: on the one hand, she said that she does not notice disconnections yet cannot present examples of connections fluently. Furthermore, she stated that it is important to establish connections and that she does so weekly, and finally, she does not succeed in the task of exemplifying when asked for three more examples.

Nonetheless, we consider that this panorama has internal coherence with what the teacher makes explicit at the beginning of the interview, when she states that the course serves the main purpose of training the teacher in their mathematical culture rather than in their role as a mathematics teacher of secondary education.

\section{Teacher Educator F2}

F2 explained the importance of the course she teaches (Calculus 1, with seven years of experience teaching it) by pointing out that prospective teachers must know the contents they will have to teach in the future in depth because: "to be able to teach [mathematics] you need to know mathematics as the first fundamental requirement" (F2). She emphasized that prospective teachers need to learn beyond what they should explicitly teach: "if one wants to teach up to 15 , they have to know up to 100 and keep 85 to themselves" (F2).

Regarding the connections between the course she teaches and the mathematics prospective teachers will teach, F2 recognized that establishing connections is difficult, and emphasized the need for teacher educators to contribute to solving this problem. She suggested that teacher educators need to develop teaching practices that promote mathematical reflection from different areas, such as problem-solving (in mathematical contexts or not) and the history of the content to be taught. F2 did not suggest concrete connections but provided adequate guidance for teacher educators' teaching practices. Regarding how to foster connections, F2 explained that they arise from the personal reflection each future teacher must carry out:

"... Mathematical contexts or non-mathematical contexts, so that the person can have a global vision, and a mature reflection, a deeper reflection. I believe that is when the person really understands the meaning of mathematics, its definition, and all the importance it has. [...] I think this can help a prospective teacher to put it into practice with sense and meaning, on account that the person has understood that meaning. And this requires personal time. But the teacher educator who guides the training process has to provide tools to promote reflection" (F2).

Teacher educator F2 believes that making connections is a personal task that is achieved by the prospective teacher over time. The teacher educator must provide tools and guide the process, although she does not specify how.

When F2 was asked to present connections between the course she teaches and lower secondary education, she found the task extremely difficult, although she has extensive experience as a mathematics teacher and also mathematics education in teacher training. She made references to upper secondary education, pointing out the concepts of limits, derivatives, and definite integrals. Although she gave as examples of connections the concept of function and the concept of area (which she ties to the concept of integral), she referred to upper secondary education by mentioning once again the concept of limit and how it connects to the contents of rational and exponential functions taught during the first year of upper secondary education. The paradox we identified at the beginning of the interview reappears here: prospective teachers have to study mathematics because they are going to teach that discipline but, ultimately, they do not learn it concerning the contents of the lower secondary education. F2 was able to state content connections with upper secondary education topics, but only a singular one (functions) with subjects' characteristic to lower secondary education.

When the teacher educator was asked how frequently she makes these connections in her class, she answered "I have not thought about it, but whenever I can". We consider this answer to be revealing because it shows the practice of establishing connections is not planned, even though the teacher educator had previously recognized the importance and the need of doing so. The examples she gave to illustrate her ideas were related to the last year of upper secondary education. This limited repertoire of examples can be explained not only because Calculus 1 and the last year of upper secondary education mathematics course have topics in common, but also by a detail that is revealed at the end of the interview: the teacher educator works as a mathematics teacher in secondary education only at the level she refers to. In short, this teacher educator can only establish connections with the contents she teaches in secondary education.

\section{Teacher Educator F3}

Teacher educator F3 has the vision that the course he is teaching (with five years of experience teaching the Topology course) has an importance in the training of mathematics teachers due to its potential to increase the vision that a person has about mathematics; the basis is "to give prospective teachers a broader perspective of what mathematics is" (F3). 
He stated that the importance is given by the need for prospective teachers to establish relationships within the mathematics they have learned, because he considers that mathematics teachers must have a deep knowledge of those contents that must be taught in secondary education. In his own words: "for prospective teachers to be capable of making an internal reflection, which does not necessarily have to be communicated to their students, in order to better elucidate the mathematical relationships that the objects that they are going to teach in secondary education have" (F3). From this statement, it can be understood that the mathematics that is taught in Topology works individually in the prospective teacher enriching their disciplinary knowledge, and it is a knowledge reserved only for the prospective teacher, an inner knowledge that is not communicable. His point of view would be aligned with a contemplation that leads to interior illumination and that, apparently, does not affect the practical action of the teacher in his secondary education classroom. Or at least, it does not explain how that knowledge could enlighten the task of the secondary school teacher even when it is not a specific subject of study at secondary level.

He pondered on the problem that students cannot connect the contents they learn in teacher training and those they must teach. Not only did he recognize this phenomenon, but he also attributed part of the responsibility to the teacher educators, and the lack of reflection that is made in this regard: "it may be because of the things we [mathematics teacher educators] do not do, that is, to connect the contents of advanced mathematics courses with the contents that prospective teachers must teach in secondary education" (F3). Although he stated that it is a complex phenomenon, he considers that teacher educators should take the time to analyze the contents of secondary education, the textbooks, to find and be able to make those connections explicitly in their classrooms.

When he was asked to find connections between the contents of the course he teaches and those of basic secondary education, he did not manage to find them but referred to the contents of upper secondary education. That is, he raised content connections, relating to the concept of limit and the theorem on the uniqueness of limits, the intermediate value theorem, and the Weierstrass theorem, in particular. More specifically, these are contents that can be found in the last year of upper secondary education. This could be because the trainer has very little teaching experience in lower secondary education. An interesting detail is the fact that he mentions other types of connections, which are related to teaching practice. That is, disciplinary practice connections: "perhaps what I can say, but I am not answering your question, it is a bit the spirit that Topology has, which is a spirit that at times can be somewhat ludic, in terms of, well, sometimes a required demonstration can involve a certain amount of ingenuity, and sometimes this kind of activity is proposed" (F3). And although he considers that it is important to establish such connections, he acknowledged that he does so circumstantially in his practice, and names the examples listed above, all referring to the contents of upper secondary education.

A dissociation can be identified between what he considers should be done and how he ultimately acts in his professional practice.

\section{Teacher Educator F4}

Teacher educator F4 bases the need for the course she dictates (Mathematics Fundamentals, with 7 years of experience in teaching this course) on the contents that it involves, because the vast majority are contents that prospective teachers will then have to teach in secondary education.

F4 recognizes the problem of disconnection that prospective teachers show in terms of the contents studied in their career and those they will eventually have to teach, but she cannot understand why this phenomenon occurs: "It is something that I sometimes find hard to understand, in the sense that there are some students, that you later see them teaching certain topics that were taught in my class, and you have to tell them: why don't you draw on what we saw and what we studied?" (F4). The teacher educator perceives in her practice the same problems that Ticknor (2012) detects in her study. We highlight here the value of the knowledge that is acquired in the practice of the teacher educator itself.

Initially, when asked about possible connections between the course she is teaching and the contents of lower secondary education, the teacher raised the contents of the divisibility of natural numbers, set theory (and its implicit use in basic secondary education), and the concept of function (recognizing its use at all levels of secondary education); and recognized the importance of making those connections visible. Notwithstanding, in addition, she admitted that she does not establish such connections very frequently in her classroom practice. That is, she acknowledges the students' difficulty, yet does not spend time establishing these connections for various reasons. In part, she attributed this to the number of contents she has to cover in her course. It seems something more circumstantial than premeditated, a spark of the moment: "whenever I can, you know? I'm teaching something and I see the possibility of saying, 'you studied this in secondary education', 'it looks like this', or 'you have to be careful with that other because maybe you are not going to explain it like that to your high school students'." (F4). Three issues are to be highlighted here. The first one, explicitly establishing connections is not part of this teacher educator's practice, it occurs occasionally. The second one, as she has experience in secondary education, it is easier for her to establish these connections. The third one, the connections she establishes are not content connections as understood by Wasserman (2018). She [F4] did mention connections between contents, but rather with a didactic perspective and a focus on teaching at the secondary level, making explicit suggestions for teaching in secondary education. We understand that this is another type of connection, different from the four reported by Wasserman (2018), which we will call professional practice connections.

However, when more connections were requested between the contents of the course that she teaches and those of lower secondary education, she found the task difficult and referred to upper secondary education: contents referring to exponential and logarithmic functions. She attributed this difficulty to not having a very clear knowledge of the contents of basic secondary education. She then added the topic of equations, but was not able to give more examples. This seems to be inconsistent with what she declared at the beginning of the interview, when she said that the vast majority of the contents that are addressed in her subject are contents that future secondary education teachers must later on teach themselves. In short, the connections she 
presented were from her professional practice. Like with the other teacher educators, the difficulty to establish connections is attributed to the lack of experience in lower secondary education and to the classroom teaching time it consumes as well. The examples given when more were requested, corresponded to upper secondary education contents.

\section{Teacher Educator F5}

F5 bases the importance of the course she teaches (Geometry, with a 5-year experience teaching it) not so much in the content itself, but in the cognitive processes that it involves and how these are related to what the future teacher should seek for in their professional practice: "when one teaches, in addition to content, all those activities that make up mathematical reasoning have to be present, what we call mathematical work. Guessing, validating, all those kinds of things are, it seems to me, as important as the content itself" (F5). In other words, she referred to two types of connections: those of content and those of the discipline's practice.

Not only does F5 recognize the existence of a disconnection that the students show between the contents of advanced mathematics courses with the contents that they will have to teach later on, but she also suggests that it is widely believed that students should be able to establish such connections on a personal level, something also pointed out by F7.

"It seems to me that we sometimes believe that by knowing wise knowledge, referring to the mathematics mathematicians use, and by having knowledge about didactics then the students are going to join one thing with the other by themselves. And it is proven that it does not happen" (F5).

Perhaps F5 and F7 share this idea because they both teach Mathematics Didactics as well.

She denied that these connections occur naturally and explicitly declared that it is necessary for the teacher educator, from their respective course, to make these connections visible. She suggested as a hypothesis that these disconnections may appear because of the differences in depth in which the contents in secondary education and advanced mathematics are taught, causing prospective teachers to not clearly recognize the same content at the different educational levels. The issue of distance reappears here, which was pointed out by other trainers and which leads some of them to be able to establish connections only when what they teach is very close to that which is taught in secondary education (also reported in the interview with F6).

As for recognizing connections between contents, F5 identified general topics, which involve: triangles (and working with polygons in general), locus, and isometries. These are content connections. She pointed out the importance of making these connections and said that she usually makes them unconsciously, even if it is not something expressly set in the course curriculum, perhaps because she works in secondary education as well and is in contact with both levels. We observe a difference with other teacher educators, who justify the difficulty of finding connections with secondary education in their lack of experience at this level. F5 has extensive experience in secondary education which makes it easier for her to identify connections. In addition, she argues that not only is the content important, so is the way of teaching it, which must be preached by example: "the way of teaching is fundamental because I think there is nothing better than a good example. Because I can talk a lot, but it also has to do with the way I work, reflect, make what I want explicit in some way, that link I want between advanced mathematics courses and what has to be taught in secondary education" (F5). This could be related to the modeled instruction connections pointed out by Wasserman (2018), and already studied by, for instance, Rojas et al. (2021), where teacher educators try to establish connections with secondary education through their own educational practices.

\section{Teacher Educator F6}

F6 justified the importance of the courses that she teaches in teacher training (Mathematics Fundamentals, Geometry, and Linear Algebra, with 20 years of experience teaching them) from various perspectives. Firstly, the mathematical culture mathematics teachers must have, and therefore must know the different areas of mathematics "every mathematics teacher must know the different areas of mathematics" (F6). Secondly, she raised the need for mathematics teachers to have a global vision of the contents that they have learned in secondary education, and understand the connections that exist between contents that (when they learned them in secondary education) seemed distant: "because they finish secondary education with a mathematics that is completely compartmentalized" (F6). Finally, she said that prospective teachers must know those contents that they will have to teach later on in depth, and how to teach them in secondary education.

Regarding the disconnection between the contents that are learned in advanced mathematics courses and those that are taught in secondary education, F6 considers that it is closely tied to the practices of the teacher educators and the groups of teachers each teacher training institution has. More notably, she suggested that, on the one hand, advanced mathematics teachers focus too much on the particular contents of their course, and do not take time to establish connections between these and the contents of secondary education; and on the other hand, Mathematics Didactics teachers often focus on general questions of didactics and do not work on these connections specifically. She also considers that there are courses that are too loaded with content, which presents obstacles for the teacher educator, since they may prefer to teach all the content rather than stopping to analyze the connections and then leave content unaddressed due to lack of time.

When F6 was questioned about connections between the contents of her course and those of lower secondary education, she identified the following contents: numerical structures (real numbers and natural numbers), divisibility, operations (with whole numbers) and isometries. As for the relevance of establishing such connections in her class, she emphasized that it is not only pertinent, but indispensable. Particularly, because Didactics teachers do not have to be specialized in all the contents that involve the mathematics in the career, and do not have time to address all the connections that may exist either, just some isolated examples. In the words of F6: "Didactics teachers, with a course that has three hours of class per week, cannot address all these aspects, or all the mathematical topics and their application to the mathematics classroom. You may work through a didactic unit to delve into a particular topic, but you can't tackle everything. So, each specific course must address things about these issues 
that have to be worked on in secondary education". For this to be accomplished, she also highlighted the importance of the teacher educator having experience in secondary education.

F6 stated that she makes these connections very frequently in her practice, but that it depends a lot on what topic she is working on at the moment. On the one hand, the teacher stated that addressing the connections is essential, yet on the other, she expressed that such an approach depends on the content. Thus, there are contents, such as natural number and divisibility, where work on connections occurs "in all classes, in all exercises or in many exercises" (F6). But there are others (for example, complex numbers) that the students have studied in the last years of secondary education and that do not require as much analysis: "the leap that must be made from what I teach in Mathematics Fundamentals to that which I teach in secondary (education) is shorter. Then it requires less analysis" (F6). She did not express that she does not make connections, but did state that she establishes them "at specific moments. Not always" (F6). Thus, recognizing that those contents which she considers closest to teacher training do not require the establishment of as many connections, assuming that the didactic transposition to be carried out in secondary education is done almost in symmetry to what is taught in teacher training.

When requested more connections between the contents of her course and those of lower secondary education, she proposes the set theory, "generally, the structure of sets is taught as the years go by [in secondary education]" (F6), the concept of function, and polynomials (and polynomial functions). This teacher educator only established content connections.

\section{Teacher Educator F7}

F7 gives a very important place to the Geometry and Linear Algebra course that he dictates (with 2 years of experience teaching it) for two reasons: one related to mathematical culture (enriching their disciplinary knowledge) and the other related to the mathematical contents of secondary education.

In addition, he admitted to having observed a disconnection between the contents that prospective teachers learn in advanced mathematics and those of secondary education. He considers that it may be due to the fact that students compartmentalize the knowledge they learn in advanced mathematics in one place, and that which they learned in secondary school and will eventually have to teach in another. In other words, he placed the responsibility of establishing these connections on the students and pointed out that over the years prospective teachers will establish them: "Apparently, it is difficult to establish that link. It seems to me that over the years, in many cases, these connections gradually strengthen" (F7).

The teacher educator presented the following examples of connections between the course he teaches and the contents of lower secondary education: systems of linear equations, linear functions and vector spaces, associated with vectors when dealing with translations. He suggested that it is important for teacher educators to establish these links in their own classes, and that he does it: "Do you see this, students? It's what you are going to teach later on" (F7). He adds that joint work with Didactics teachers would be good, which suggests that perhaps the connections he referred to are not strictly about content, but also about professional practice connections.

On the other hand, although he considers it very important to make such connections, he said he does it in those situations in which the connections are more evident: "when a topic that is very related is presented, we are working on a topic that is practically a content that they are going to teach [...], there I stop and try to build that bridge" (F7). That is, he makes connections when the content to be taught is very close to what the prospective teacher is going to teach. This is aligned, as we will see, with what F8 expresses.

The trainer finds, without too much of a hassle, more examples of connections between contents: geometric transformations (isometries, similarities), area calculations (in teacher training associated with the calculation of determinants), and even with mathematical aspects that are studied in basic secondary education in other courses (he mentions physics), where he analyzes the internal product and how the product of vector magnitudes (force and distance) results in a scalar magnitude (work). But this contrasts with the time he spends making those connections visible in his practice, since he makes them "whenever I consider it relevant" (F7) and we once again emphasize that this refers to content that is very close between both levels.

\section{Teacher Educator F8}

F8 justified the importance of the subject he dictates (Probability and Statistics, with twelve years of experience) with the applications it has in the modeling of reality. He also justified its importance with the possibility that it offers prospective teachers for involving their students in solving problems, particularly related to everyday situations that handle uncertainty. He maintains that this gives them tools to foster motivation in their classes.

Regarding the disconnections that prospective teachers may have between the contents of their career and those of secondary education, F8 was cautious in his statements, although he recognizes the existence of the problem. He considers that it is due to the fact that there is a great difference between one level and the other, and how teacher educators focus mainly on the depth of the contents and not on how they should be brought into the classroom.

"I think there is a big difference, and I think that many times teacher educators they, we, also focus on a lot of things that we think they must know, and types of approaches, and theorems, and things like that, harder, and not so much on how to put them into practice in a classroom and things like that" (F8).

This approach makes us think that he is mainly referring to professional practice connections and not necessarily those of content, due to his emphasis on the "how".

F8 identified the following connections between the contents of his course and those of secondary education: Bayes' theorem and descriptive statistics in general (tables, mean, median, mode, variances), although he hesitated a bit when referring to lower secondary education, justifying this in the fact that he has never worked in that context. And although he considers it important 
to establish these connections in his class, he reaffirmed those doubts regarding lower secondary education, stating that he was not sure if he established links with that level, and referred to his experience in upper secondary education: "I don't know if specifically, for lower secondary education, because I do not have experience at that level. I have experience in upper secondary education in technical education, which is also secondary education" (F8). He said he believes he establishes connections very frequently (if not in all classes, at least weekly), but that "no one is very objective when talking about themselves" (F8) and "someone else would have to say it" (F8). If he does indeed make these connections, it could be understood from his speech that they would focus on upper secondary education since the teacher acknowledges that he has no experience in basic secondary education. In addition, he presented how choosing to use GeoGebra software can provide a basis for establishing such connections "it perfectly serves as a connection with fairly basic levels. Things like that" (F8), but the emphasis he made regarding his ignorance of lower secondary education, leads to thinking that the connections he makes are more related to upper secondary education, as mentioned above. However, this could be considered as a modeled instructional connection since the teacher chooses to use this software instead of others that are more appropriate for the course he teaches, based on the fact that it is possible to use it for the teaching of basic contents that will be the ones that prospective teachers will eventually teach in secondary education. In addition, he pointed out that even though this software presents more errors in the results it gives for mathematical models, he uses those errors to set up debates in the classroom, which is also a recommended practice for secondary education.

Technical upper secondary education is the only level of secondary education in which he has taught: "I have experience in upper secondary education in technical education" (F8). In any case, when questioned, he presented new examples of connections: graphs (histograms, pictograms, circular diagrams), classical probability linked to chance, and subjective probability.

From his speech, it appears that this teacher educator is able to establish connections with the contents of secondary education courses in which he has had teaching experience. In his particular case, the experience is exclusively in technical upper secondary education. The teacher focused his arguments for not being able to offer more connections in his lack of experience in, for example, lower secondary education.

\section{DISCUSSION}

Most of the teacher educators interviewed recognize that, in the training of mathematics teachers, there is a lack of connection between the advanced mathematics that is taught in the career and that which the students, prospective teachers, will have to teach in their classes. In general, although they do observe the disconnections, they do not detect them in their own classes. Seven out of eight of the interviewees recognize this problem.

When asking the teacher educators to present examples of connections, five of them (F2, F3, F5, F6, and F8) were able to do so. F2, F3, F4, and F8 established connections with the secondary education level in which they teach and some of them explicitly mentioned that not working in lower secondary education presents itself a difficulty for them to establish connections. In general, the content connections they mentioned referred to upper secondary education contents that appear in the curriculums at that level, in a very similar way to how they do in the those of teacher training mathematics courses, for example, complex numbers. This is the case of F7 and F8 who only establish connections with neighboring topics between teacher training and secondary education. The difficulty in establishing connections with the contents of lower secondary education is notorious. Those who managed to do so were the ones who have teaching experience at that level. Conversely, having taught mainly at the upper secondary level comes up as an obstacle to identify connections with lower secondary education. Some teachers explicitly expressed that not working in lower secondary education represented a difficulty for them to establish connections. This invites us to ponder over the importance of teacher educators having worked as teachers at all levels of secondary education and having vast experience of what is taught and learned there.

In the interviews, other kinds of connections were identified in addition to content connections: discipline practice connections (F3 and F5) and modeled instruction connections (F5 and F8). Disciplinary practice connections were manifested at the time of justifying the importance of the subject they teach and those of modeled instruction when they justified that they used certain methodological constructions in their classrooms because they were working on teacher training.

Additionally, in the interviews we have identified references to what seems to be another kind of connection, not reported by Wasserman (2018), which refers to the didactic recommendations made by the teacher educators taking into account the professional future of their students. They do not refer to issues that the trainers apply or implement in their own classroom practice taking into account that they train teachers. Instead, teacher educators refer to suggestions that they make to their students to address issues at secondary level education for when they are teaching in front of a classroom in the future. We have provisionally called this type of connection professional practice connections and it was identified in the interviews with teacher educators F4 and F8. Certainly, more research is needed to refine and delve into this type of connection.

\section{CONCLUSIONS}

This work aimed to identify which mathematical connections eight mathematics teacher educators could establish between the contents of the course they teach and the mathematics that prospective teachers will have to teach in secondary education.

Seven out of the eight teachers interviewed recognized the problem related to the lack of connections between what is taught in the mathematics courses of the career and the mathematics that they must teach in secondary education. They were all able to 
establish connections between the contents of the course they teach and the mathematics of secondary education. Even though the focus was mainly put on content connections, two other types of connections were observed as well, as outlined by Wasserman (2018). The connections identified were content connections, modeled instruction connections, and disciplinary practice connections. Furthermore, for two of the teacher educators, the mathematical connections with lower secondary education refer to connections that we have called professional practice connections.

However, the content connections established were, mainly, with upper secondary education content. Serious difficulties were evident when attempting to establish content connections with lower secondary education due to the fact that, in the words of the teachers themselves, they have not taught at that level. Additionally, teacher educators can establish mathematical connections more easily with content that appears practically symmetrically in teacher training curriculums and in upper secondary education curriculums.

The analysis of the interviews suggests that the teacher educators do not, generally speaking, approach work with the connections between the mathematics they teach and that which their students will teach in a systematic and planned way. There were three main difficulties identified: the fact that they do not have time, that it is something that should be left to the person who is in training and will be acquired in professional practice, or that they are unaware of the connections because they have not worked in lower secondary education. We understand that identifying these connections and making them explicit in the teacher training classroom is paramount in order to improve the quality of such education.

Author contributions: All authors have sufficiently contributed to the study, and agreed with the results and conclusions.

Funding: No funding source is reported for this study.

Declaration of interest: No conflict of interest is declared by authors.

\section{REFERENCES}

Leikin, R., Zazkis, R., \& Meller, M. (2018). Research mathematicians as teacher educators: Focusing on mathematics for secondary mathematics teachers. Journal of Mathematics Teacher Education, 21, 451-473. https://doi.org/10.1007/s10857-017-9388-9

Marshman, M. (2021) Learning to teach mathematics: How secondary prospective teachers describe the different beliefs and practices of their mathematics teacher educators. In M. Goos \& K. Beswick (Eds.), The learning and development of mathematics teacher educators (pp. 123-144). Springer. https://doi.org/10.1007/978-3-030-62408-8_7

Rojas, F., \& Deulofeu, J. (2015). El formador de profesores de matemática: Un análisis de las percepciones de sus prácticas instruccionales desde la «tensión» estudiante-formador [The teacher educator of mathematics: An analysis of the perceptions of their instructional practices from the student-teacher "tension"]. Enseñanza de las Ciencias [Science Teaching], 33(1), 47-61. http://dx.doi.org/10.5565/rev/ensciencias.1322

Rojas, F., Montenegro, H., Goizueta, M., \& Martínez, S. (2021) Researching modelling by mathematics teacher educators: Shifting the focus onto teaching practices. In M. Goos \& K. Beswick (Eds.), The learning and development of mathematics teacher educators (pp. 367-382). Springer. https://doi-org.proxy.timbo.org.uy/10.1007/978-3-030-62408-8_19

Suominen, A. (2018). Abstract algebra and secondary school mathematics connections as discussed by mathematicians and mathematics educators. In N. Wasserman (Ed.), Connecting abstract algebra to secondary mathematics, for secondary mathematics teachers (pp. 149-173). Springer. https://doi.org/10.1007/978-3-319-99214-3_8

Ticknor, C. S. (2012). Situated learning in an abstract algebra classroom. Educational Studies in Mathematics, 81, $307-323$. https://doi.org/10.1007/s10649-012-9405-y

Wasserman, N. (2018). Exploring advanced mathematics courses and content for secondary mathematics teachers. In N. Wasserman (Ed.), Connecting abstract algebra to secondary mathematics, for secondary mathematics teachers (pp. 1-15). Springer. https://doi.org/10.1007/978-3-319-99214-3_1

Weber, K., Mejía-Ramos, J., Fukawa-Connelly, T., \& Wasserman, N. (2020). Connecting the learning of advanced mathematics with the teaching of secondary mathematics: Inverse functions, domain restrictions, and the arcsine function. The Journal of Mathematical Behavior, 57, 1-21. https://doi.org/10.1016/j.jmathb.2019.100752

Winsløw, C., \& Grønbæk, N. (2014). The ecological Klein's double discontinuity revisited: Contemporary challenges for universities preparing teachers to teach calculus. Recherches in Didactique des Mathématiques [Research in Mathematics Didactics], 34(1), 59-86.

Yan, X., Marmur, O., \& Zazkis, R. (2021). Advanced mathematics for secondary school teachers: Mathematicians' perspective. International Journal of Science and Mathematics Education. https://doi.org/10.1007/s10763-020-10146-x 